IGCS20_1049

\section{VARIATION IN PRACTICE IN ENDOMETRIAL CANCER (EC); CAN MOLECULAR CLASSIFICATION DIRECT CARE AND REDUCE COSTS ASSOCIATED WITH MANAGEMENT?}

${ }^{1} \mathrm{E}$ Thompson*, ${ }^{1} \mathrm{~A}$ Lum, ${ }^{1} \mathrm{~J}$ Huvila, ${ }^{2} \mathrm{~S}$ Scott, ${ }^{1} \mathrm{~V}$ Lui, ${ }^{1} \mathrm{E}$ He, ${ }^{1} \mathrm{~T}$ Salisbury, ${ }^{3} \mathrm{~S}$ Keane, ${ }^{3} \mathrm{~S}$ Keane, ${ }^{4} \mathrm{~V}$ Samouelian, ${ }^{1} \mathrm{~J}$ Irving, ${ }^{5} \mathrm{~S}$ Salvador, ${ }^{6} \mathrm{~L}$ Helpman, ${ }^{7} \mathrm{C}$ Wohlmuth, ${ }^{8} \mathrm{M}$ Kinloch, ${ }^{2} \mathrm{~S}$ Offman, ${ }^{7} \mathrm{D}$ Vicus, ${ }^{9} \mathrm{~K}$ Grondin, ${ }^{5} \mathrm{~W}$ Gtlieb, ${ }^{9} \mathrm{M}$ Plante, ${ }^{1} \mathrm{D}$ Huntsman, ${ }^{1} \mathrm{~A}$ Talhouk, ${ }^{1} \mathrm{CB}$ Gilks, ${ }^{1} \mathrm{G}$ Hanley, 'J McAlpine. 'University of British Columbia and BC Cancer, Canada; ${ }^{2}$ Genetic Pathology Evaluation Center, Canada; ${ }^{3}$ Dalhousie University Medical School, Canada; ${ }^{4}$ Centre hospitalier de I'Université de Montréal, Canada; ${ }^{5}$ McGill University, Canada; ${ }^{6}$ McMaster University and the Juravinski Cancer Center, Canada; ${ }^{7}$ Sunnybrook Health Sciences Center, Canada; ${ }^{8}$ University of Saskatoon, Canada; ${ }^{9}$ Université Laval, Canada

\subsection{6/ijgc-2020-IGCS.6}

Objectives We wished to assess the potential impact of directing EC management based on molecular classification, and the projected cost implications of molecular subtype-directed care. Methods Surgical staging, treatment, surveillance, and hereditary cancer program(HCP) referrals were assessed for all ECs managed in a single calendar year (2016) across 24 Canadian centers. Variation of practice was recorded, as well as where a change in management would be projected and associated cost implications of that change based on molecular subtype assignment.

Results Data from 862 patients revealed wide variation in surgical staging, with lymph node dissection(LND) performed in $61 \%$ of ECs (range 25-100\%), including 38\% LND in Gr1ECs (0100\%). Adjuvant therapy (type, when/if given) and cancer surveillance (frequency, site e.g., community vs. cancer center) was inconsistent within and across centers for both early-and latestage disease. Molecular classification identified 29\% MMRd ECs $(n=247)$ but only $8 \%$ of these women had been referred to HCP. 30 women who did consult HCP were MMRproficient. $38 \%$ of MMRd ECs had no LND and 43\% did not receive radiation. $16 \%$ and $18 \%$ of p53abn ECs had no LND or omentectomy respectively, and only 58\% received chemotherapy. Deescalation of treatment in early-stage POLEmut and NSMP ECs $(n=63$ treated, where molecular classification would direct observation or brachytherapy-only) would have reduced costs by $\$ 348,896-407,830 \mathrm{CAD}$ or \$5538-6466CAD per patient.

Conclusions There is currently profound variation in practice for all aspects of EC management with implications to patients and health systems. Molecular classification can provide consistency in care and direct biologically-informed management.

\section{IGCS20_1231}

\section{\begin{tabular}{l|l}
7 & SENTINEL LYMPH NODE BIOPSY VERSUS
\end{tabular} LYMPHADENECTOMY FOR INTERMEDIATE AND HIGH GRADE ENDOMETRIAL CANCER STAGING (SENTOR TRIAL): A PROSPECTIVE MULTICENTER COHORT STUDY}

\footnotetext{
${ }^{1} \mathrm{M}$ Cusimano*, ${ }^{2} \mathrm{D}$ Vicus, ${ }^{3} \mathrm{~K}$ Pulman, ${ }^{4} \mathrm{MQ}$ Bernardini, ${ }^{4} \mathrm{G}$ Bouchard-Fortier, ${ }^{4} \mathrm{~S}$ Laframboise, ${ }^{4} \mathrm{~T}$ May, ${ }^{4} \mathrm{~L}$ Hogen, ${ }^{2} \mathrm{~A}$ Covens, ${ }^{2} \mathrm{LT}$ Gien, ${ }^{2} \mathrm{R}$ Kupets, ${ }^{4} \mathrm{M}$ Rouzbahman, ${ }^{4} \mathrm{BA}$ Clarke, 2) Mirkovic, ${ }^{3} \mathrm{M}$ Cesari, ${ }^{5} \mathrm{G}$ Turashvili, ${ }^{4} \mathrm{M}$ Maganti, ${ }^{4} \mathrm{~A}$ Zia, ${ }^{4} \mathrm{GEV}$ Ene, ${ }^{4} \mathrm{~S}$ Ferguson. ${ }^{1}$ University of Toronto, Canada; ${ }^{2}$ Sunnybrook Health Sciences Centre, Canada; ${ }^{3}$ Trilium Health Partners, Canada; ${ }^{4}$ University Health Network, Canada; ${ }^{5}$ Sinai Health Systems, Canada
}

10.1136/ijgc-2020-IGCS.7
Background It is unclear whether sentinel lymph node biopsy (SLNB) can replace lymphadenectomy in women with high grade endometrial cancer (EC). We performed a prospective multicenter cohort study (the SENTOR trial) to evaluate the diagnostic accuracy of SLNB using indocyanine green in intermediate and high grade EC (NCT01886066).

Methods Patients with clinical stage I grade 2 endometrioid or high grade EC scheduled for minimally invasive hysterectomy at three academic centers in Toronto, Canada, were prospectively enrolled for SLNB followed by pelvic (PLND) and paraaortic lymphadenectomy (PALND) as the reference standard. The study was powered to determine sensitivity of the SLNB algorithm as the primary endpoint.

Results We enrolled 156 patients (126 high grade); all underwent SLNB and PLND, and 106 (84\%) with high grade EC underwent PALND. Sentinel lymph node detection rates were $97 \%$ per patient (95\% CI 94-99), 88\% per hemipelvis (95\% CI 83-91), and 78\% bilaterally (95\% CI 70 84). Of 27 patients (17\%) with nodal metastases, 26 were correctly identified by the SLNB algorithm, yielding a sensitivity of $96 \%$ (95\% CI $81-100)$, false negative rate of $4 \%$ (95\% CI $0-19)$, and negative predictive value of $99 \%(95 \%$ CI 96-100). Only one patient $(0.6 \%)$ was misclassified by the SLNB algorithm. Two of 27 node-positive patients (7.5\%) were identified outside traditional PLND boundaries, and five of $27(18.5 \%)$ required immunohistochemistry for diagnosis.

Conclusion SLNB has comparable, if not superior, diagnostic accuracy relative to lymphadenectomy in high grade EC patients. SLNB is a viable option for the surgical staging of EC.

\section{IGCS20_1246}

\section{A MULTICENTRIC RANDOMIZED TRIAL TO EVALUATE THE ROLE OF UTERINE MANIPULATOR ON LAPAROSCOPIC/ROBOTIC HYSTERECTOMY FOR THE TREATMENT OF LOW-RISK ENDOMETRIAL CANCER: THE ROMANHY TRIAL (NCT:02762214)}

${ }^{1} \mathrm{~S}$ Gueli Alletti ${ }^{*},{ }^{1} \mathrm{E}$ Perrone, ${ }^{1} \mathrm{C}$ Fedele, ${ }^{1} \mathrm{G}$ Vizzielli, ${ }^{1} \mathrm{~A}$ Fagotti, ${ }^{1} \mathrm{~V}$ Gallotta, ${ }^{1} \mathrm{C}$ Rossitto, ${ }^{1} \mathrm{~B}$ Costantini, ${ }^{1} \mathrm{~S}$ Restaino, ${ }^{1} \mathrm{G}$ Monterossi, ${ }^{1} \mathrm{~F}$ Fanfani, ${ }^{1} \mathrm{G}$ Scambia, ${ }^{2} \mathrm{~S}$ Cianci, ${ }^{3} \mathrm{~V}$ Chiantera, ${ }^{4} S$ Uccella, ${ }^{5}$ A Ercoli. ${ }^{1}$ Division of Gynecologic Oncology, Fondazione Policlinico Universitario A. Gemelli IRCCS, Italy; ${ }^{2}$ Department of Woman, Child and General and Specialized Surgery, University of Campania 'Luigi Vanvitelli', Italy; ${ }^{3}$ Department of Gynecologic Oncology, ARNAS Civico Di Cristina Benfratelli, Università di Palermo, Italy; ${ }^{4}$ Department of Obstetrics and Gynecology, AOUI Verona, Università di Verona, Italy; ${ }^{5}$ Division of Obstetrics and Gynecology, Università degli studi di Messina, Policlinico G. Martino, Italy

\subsection{6/ijgc-2020-IGCS.8}

Background The role of the intrauterine manipulator in minimally invasive hysterectomy for endometrial cancer has been widely debated in terms of impact on the oncological outcomes. To date, definitive conclusions on the possible advantages and oncological safety of its use in endometrial cancer staging are still awaited.

Objectives This randomized trial aimed to assess the role of the uterine manipulator in terms of oncological and perioperative outcomes in patients undergoing minimally invasive (laparoscopic/robotic) staging for presumed low-risk endometrial cancer. 